lodine-129 Analysis of NTS Near-Field Groundwater Samples on the Multi-Collector ICP-MS

R. Williams, E. Ramon, J. E. Moran, T. P. Rose

February 14, 2005

\title{
UCRL-TR-209681
}


This document was prepared as an account of work sponsored by an agency of the United States Government. Neither the United States Government nor the University of California nor any of their employees, makes any warranty, express or implied, or assumes any legal liability or responsibility for the accuracy, completeness, or usefulness of any information, apparatus, product, or process disclosed, or represents that its use would not infringe privately owned rights. Reference herein to any specific commercial product, process, or service by trade name, trademark, manufacturer, or otherwise, does not necessarily constitute or imply its endorsement, recommendation, or favoring by the United States Government or the University of California. The views and opinions of authors expressed herein do not necessarily state or reflect those of the United States Government or the University of California, and shall not be used for advertising or product endorsement purposes.

This work was performed under the auspices of the U.S. Department of Energy by University of California, Lawrence Livermore National Laboratory under Contract W-7405-Eng-48. 


\section{lodine-129 Analysis of NTS Near-Field Groundwater Samples on the Multi-Collector ICP-MS}

Ross Williams, Erick Ramon, Jean Moran, and Timothy Rose

Chemical Biology and Nuclear Science Division

Lawrence Livermore National Laboratory

September 2003 


\title{
lodine-129 Analysis of NTS Near-Field Groundwater Samples on the Multi-Collector ICP-MS
}

\author{
Ross Williams, Erick Ramon, Jean Moran, and Timothy Rose \\ Chemical Biology and Nuclear Science Division, Lawrence Livermore National Laboratory
}

\section{Executive Summary}

Iodine was chemically separated from NTS near-field groundwater samples and analyzed for its ${ }^{129} \mathrm{I} /{ }^{129} \mathrm{I}$ ratio on a Multi-Collector Inductively Coupled Plasma Mass Spectrometer (MC-ICPMS). The measured ratios were then compared to ${ }^{129} \mathrm{I} /{ }^{129} \mathrm{I}$ ratios for identical samples run on the Accelerator Mass Spectrometer (AMS). The MC-ICPMS results in some cases differed from the AMS values by more than an order of magnitude. The disparity in the results is due to isobaric interferences at mass 129 from polyatomic species and ${ }^{129} \mathrm{Xe}$ in the MC-ICPMS plasma gas. It is anticipated that the interferences can be largely eliminated by (1) improving the molybdenum separation chemistry using a ${ }^{92} \mathrm{Mo}$-spike precipitation method, and (2) introducing $\mathrm{O}_{2}$ to the plasma gas to reduce the ${ }^{129} \mathrm{Xe}$ interference. The MC-ICPMS detection limit for ${ }^{129} \mathrm{I} /{ }^{127} \mathrm{I}$ (measured on reference standards) is on the order of 1E-6 or slightly lower. Most near-field groundwater samples have ${ }^{129} \mathrm{I} /{ }^{127} \mathrm{I}$ ratios $>1 \mathrm{E}-6$, and should be measurable on the MC-ICPMS once the isobaric interference issues are resolved.

\section{Introduction}

Iodine has one stable isotope $\left({ }^{127} \mathrm{I}\right)$ and one long-lived naturally occurring radioisotope $\left({ }^{129} \mathrm{I}\right)$ with a half-life of $1.57 \times 10^{7}$ years. Prior to nuclear weapons testing, natural ${ }^{129} \mathrm{I} /{ }^{127} \mathrm{I}$ ratios in the atmosphere were on the order of $10^{-12}$ (Fehn et al., 1986; FabrykaMartin et al., 1987; Moran et al., 1998). Groundwater that recharged prior to atmospheric testing typically has ${ }^{129} \mathrm{I} /{ }^{127} \mathrm{I}$ ratios in the $10^{-12}$ to $10^{-14}$ range (Fabryka-Martin, 2000).

Iodine-129 comprises approximately $1 \%$ of the fission products produced by nuclear tests, and occurs as a largely non-reactive, mobile anion in groundwater. Data presented in this report show that groundwater samples from underground test cavities at the Nevada Test Site (NTS) in some cases have ${ }^{129} \mathrm{I} /{ }^{127} \mathrm{I}$ ratios as high as $10^{-2}$. Iodine-129 is conventionally measured on the Accelerator Mass Spectrometer (AMS), which has the sensitivity necessary to detect natural environmental concentrations. However, the ${ }^{129} \mathrm{I} /{ }^{127} \mathrm{I}$ ratios found in the near-field environment at the NTS are sufficiently elevated to where they should also be measurable using the latest generation of Multi-Collector Inductively Coupled Plasma Mass Spectrometers (MC-ICPMS).

This report summarizes the results of a feasibility study designed to test the capabilities of the MC-ICPMS for ${ }^{129} \mathrm{I} /{ }^{127} \mathrm{I}$ analysis of NTS near-field groundwater samples. 
Instrument detection limits were determined using reference standards with known ${ }^{129} \mathrm{I} /{ }^{127} \mathrm{I}$ ratios. A procedure for pre-concentrating iodine in natural waters was developed and is fully documented in Appendix A of this report. Archival near-field groundwater samples were analyzed on both the MC-ICPMS and AMS, so that the results of the new technique could be directly compared with the standard method of ${ }^{129} \mathrm{I} /{ }^{127} \mathrm{I}$ analysis.

\section{Chemical Purification of lodine from Groundwater Samples}

The procedure used to extract and purify the iodide anion $\left(\mathrm{I}^{-}\right)$from near-field water samples is described in Appendix A. Here we will briefly summarize the methodology. Water samples should be preserved in the field using $5 \mathrm{~mL}$ of $0.1 \mathrm{M}$ hydroxylamine hydrochloride per liter of water. Once the samples are returned to the lab, the chloride $\left(\mathrm{Cl}^{-}\right)$and iodide $\left(\mathrm{I}^{-}\right)$concentrations are measured by ion chromatography. A sample volume that is sufficient to yield at least $5 \mu \mathrm{g}$ of $\mathrm{I}^{-}$is evaporated to $20 \%$ of its initial volume and then acidified to $\mathrm{pH}<2$ with $\mathrm{HNO}_{3} .1 \mathrm{M} \mathrm{AgNO}_{3}$ solution is then added to provide a 2x stoichiometric excess of $\mathrm{Ag}^{+}$for the amount of $\mathrm{Cl}^{-}$in the sample. $\mathrm{An} \mathrm{AgCl}$ $+\mathrm{AgI}$ precipitate will form. After separating and rinsing the precipitate, the $\mathrm{AgCl}$ is dissolved in $\mathrm{NH}_{4} \mathrm{OH}$, leaving $\mathrm{AgI}$ behind as an insoluble residue. The $\mathrm{AgI}$ is then dissolved in dilute $\mathrm{KCN}$ solution ( $\mathrm{pH}$ adjusted with $\mathrm{NH}_{4} \mathrm{OH}$ ) and is passed though cation exchange resins to strip out unwanted cations. The last resin column is conditioned with $\mathrm{HCl}$, so that the final $\mathrm{I}^{-}$solution is weakly acidic. The volume can again be reduced somewhat by evaporation prior to ${ }^{129} \mathrm{I} /{ }^{127} \mathrm{I}$ analysis on the MC-ICPMS.

\section{MC-ICPMS Analytical Method}

The ${ }^{129} \mathrm{I} /{ }^{127} \mathrm{I}$ ratios of the chemically purified samples were measured on a GV IsoProbe Multi-Collector Inductively Coupled Plasma Mass Spectrometer (MC-ICPMS). The IsoProbe is a magnetic sector instrument with a high efficiency inductively coupled plasma source, hexapole collision cell, and multiple detectors capable of simultaneously collecting ${ }^{129} \mathrm{I}$ and ${ }^{127} \mathrm{I}$, thus eliminating time-related instabilities associated with plasma ionization and dramatically improving the precision on isotope ratios.

In preparation for measuring natural samples, an analytical protocol was developed using pure iodine reference standards with known ${ }^{129} \mathrm{I} /{ }^{127} \mathrm{I}$ ratios. For these standards, a $0.5 \mathrm{ml}$ solution of $0.01 \mathrm{M}$ hydroxylamine hydrochloride containing at least $5 \mathrm{E} 8$ atoms of ${ }^{129} \mathrm{I}$ was aspirated at a rate of $0.05 \mathrm{~mL} / \mathrm{min}$ using a glass expansion Micromist nebulizer into a glass expansion cinnabar-jacketed cyclonic spray chamber maintained at a constant temperature of $2^{\circ} \mathrm{C}$. The plasma source was operated at a forward power of 1350 watts while maintaining a reflected power less than 1 watt. Argon was introduced into the collision cell at a rate of $0.8 \mathrm{ml} / \mathrm{min}$ to thermalize the ion beam to a tight energy distribution for flat peak tops. Samples are bracketed with standards of known ${ }^{129} \mathrm{I} /{ }^{127} \mathrm{I}$ to correct for mass bias. The gain factor between pulse counting and faraday detectors is determined by peak jumping a ${ }^{127}$ I signal of 300,000 counts per second between both 
detectors. Blanks are run prior to all samples and standards to correct for any background contribution to the signals.

Several challenges exist that complicate the measurement of ${ }^{129} \mathrm{I} /{ }^{127} \mathrm{I}$ by MC-ICPMS. First is the presence of xenon in the argon plasma gas. ${ }^{129} \mathrm{Xe}$ creates an isobaric interference that limits the detection limit of ${ }^{129} \mathrm{I}$. To minimize this problem, oxygen can be introduced at a rate of $0.1 \mathrm{ml} / \mathrm{min}$ to $0.4 \mathrm{ml} / \mathrm{min}$ into the collision cell. By doing so, the $\mathrm{Xe}$ interference is significantly reduced and the detection limit of ${ }^{129} \mathrm{I}$ improved to approximately $5 \mathrm{E} 8$ atoms.

A second interference that limits the detection of ${ }^{129} \mathrm{I}$ is from the polyatomic cluster ${ }^{127} \mathrm{IHH}$. Unlike Xe, there is no collision gas that we've found that can reduce the production of the double hydride on iodine. Certain tuning parameters such as the hexapole DAC and extraction potential can be used to minimize double hydride production at the expense of iodine sensitivity. A correction is made by analyzing a sample with identical ${ }^{127}$ I concentration and no ${ }^{129}$ I just prior to an unknown to quantify the double hydride production. Sample matrix can affect double hydride production so extreme care must be taken to ensure that all samples are in an identical matrix. When tuned for maximum sensitivity, the detection limit for ${ }^{129} \mathrm{I}$ is $5 \mathrm{E} 8$ atoms but the production rate for ${ }^{127} \mathrm{IHH}$ is $1 \mathrm{E}-6$. The minimum ${ }^{129} \mathrm{I} /{ }^{127} \mathrm{I}$ ratio we are able to measure accurately with this tuning is $1 \mathrm{E}-6$. If $5 \mathrm{E} 10$ atoms of ${ }^{129} \mathrm{I}$ are available for analysis, the instrument can be tuned to minimize double hydride production and measure ${ }^{129} \mathrm{I} /{ }^{127} \mathrm{I}$ ratios of 1E-7. The interference from the double hydride is negligible when signal strength at mass 127 is less than $100 \mathrm{mV}$.

\section{Analysis of Near-Field Groundwater Samples by MC-ICPMS}

After establishing the detection limits and optimal tuning parameters for the MC-ICPMS, analyses were performed on chemically purified iodine samples prepared from near-field groundwater samples. These included archival samples from the post-shot holes for the Cheshire, Camembert, and Almendro underground tests. The results are summarized in Table 1. The measured ratios for these samples range from 1.9E-03 to 1.1E-04. Note that these measurements include contributions at mass 129 from ${ }^{129} \mathrm{I},{ }^{129} \mathrm{Xe}$, and ${ }^{127} \mathrm{IHH}$.

Since the ${ }^{129} \mathrm{Xe}$ signal is introduced with the argon plasma gas, an instrument "blank" is normally measured and then subtracted from the measured sample value in order to correct for this mass interference. However, when this correction was applied to the measured values, negative numbers were obtained (Table 1). The most probable explanation is that the blank ${ }^{129} \mathrm{Xe}$ signal is substantially higher than the ${ }^{129} \mathrm{Xe}$ signal measured during sample analysis. This is due to a matrix suppression effect, which causes the ${ }^{129} \mathrm{Xe}$ signal to decrease when the sample is present. Under these conditions, 
Table 1. ${ }^{129} \mathrm{I} /{ }^{127} \mathrm{I}$ analyses determined by MC-ICPMS

\begin{tabular}{lllcc}
\hline Well Name & Test Name & Sample Date & $\begin{array}{c}{ }^{129} \mathrm{I} /{ }^{127} \mathrm{I} \\
\text { (measured ratio) }\end{array}$ & $\begin{array}{c}{ }^{129} \mathrm{I} /{ }^{127} \mathrm{I} \\
\text { (blank subtracted) }\end{array}$ \\
\hline U-20n PS\#1ddh & Cheshire & 12 Oct 99 & $1.58 \mathrm{E}-04$ & $-5.55 \mathrm{E}-04$ \\
U-19q PS\#1d & Camembert & 21 Oct 98 & $1.07 \mathrm{E}-04$ & $-7.99 \mathrm{E}-03$ \\
U-19v PS\#1ds & Almendro & 18 Aug 99 & $1.86 \mathrm{E}-03$ & $-4.04 \mathrm{E}-04$ \\
U-19v PS\#1ds & Almendro & 26 Sep 00 & $5.65 \mathrm{E}-04$ & $-7.55 \mathrm{E}-04$ \\
& & & \\
Reference Standard with ${ }^{129} \mathrm{I} /{ }^{127} \mathrm{I}=$ 9.64E-05 & $3.86 \mathrm{E}-04$ & $8.86 \mathrm{E}-05$ \\
\hline
\end{tabular}

the purified sample matrix cannot be exactly matched to the bias standards and blanks, making it very difficult to correct for the ${ }^{129} \mathrm{Xe}$ interference. In a similar manner, it was found that ${ }^{127} \mathrm{IHH}$ also had a different ionization efficiency in the pure reference standard than in the sample matrix.

As noted in the preceding section, introducing oxygen gas into the collision cell can significantly reduce the Xe mass interference. However, it was found that molybdenum is not entirely removed during iodine purification, and it reacts with $\mathrm{O}_{2}$ in the collision cell to form the polyatomic species ${ }^{97} \mathrm{Mo}^{16} \mathrm{O}_{2}$, an interference at mass 129 . Therefore, the presence of Mo in the final purified solution precludes us from using $\mathrm{O}_{2}$ to reduce the interference from Xe. This forced us to deviate from the protocols developed for the pure reference standards. As a result of these limitations, the natural samples were analyzed without the use of oxygen in the collision cell and the data collected could not be corrected for background contribution from both Xe and ${ }^{127} \mathrm{IHH}$. The resulting ${ }^{129} \mathrm{I} /{ }^{127} \mathrm{I}$ calculated from the collected data should therefore be considered maximum values. Further advancing the chemistry to more effectively remove Mo and more carefully control the final matrix would allow us to follow the protocol developed for pure standards more closely.

\section{Comparison with AMS ${ }^{129} \mathrm{I} /{ }^{127}$ I Results}

In order to assess the accuracy of the MC-ICPMS ${ }^{129} \mathrm{I} /{ }^{127} \mathrm{I}$ data, an independent set of ${ }^{129} \mathrm{I} /{ }^{127} \mathrm{I}$ analyses were performed on the accelerator mass spectrometer (AMS). The AMS is the standard technique for iodine isotope ratio measurements. Splits of three samples that were analyzed by MC-ICPMS were also analyzed at the Canadian Center for Accelerator Mass Spectrometry at the University of Toronto. The AMS results are reported in Table 2. The ${ }^{129} \mathrm{I} /{ }^{127} \mathrm{I}$ results for several samples that were not measured on the MC-ICPMS were also included in Table 2 to illustrate the range in values that are observed in NTS near-field groundwaters. 
The first three rows in Table 2 show the AMS ${ }^{129} \mathrm{I} /{ }^{127} \mathrm{I}$ results for the same set of samples that appear in the first three rows of Table 1 (measured by MC-ICPMS). A comparison of these data reveals that the MC-ICPMS ${ }^{129} \mathrm{I} /{ }^{127} \mathrm{I}$ ratio for Cheshire is a factor of three greater than the AMS Cheshire value, while the MC-ICPMS analysis for Camembert is nearly 50 times the AMS result. These data demonstrate how the contribution from interfering masses can strongly affect the measured signal at mass 129 during $\mathrm{MC}$ ICPMS analysis. Note also that the MC-ICPMS results for Cheshire and Camembert differ by only a factor of 1.5 despite the fact that the AMS results show their ${ }^{129} \mathrm{I} /{ }^{127} \mathrm{I}$ ratios differ by more than an order of magnitude. Background interferences from ${ }^{129} \mathrm{Xe}$ (and perhaps ${ }^{127} \mathrm{IHH}$ ) likely comprise a large fraction of the mass 129 signal for the Cheshire sample, and nearly all the measured signal for Camembert.

Comparison of the August 1999 Almendro data reveals that the ${ }^{129} \mathrm{I} /{ }^{127} \mathrm{I}$ ratio measured on the MC-ICPMS is actually a factor of four less than the AMS ratio. We do not presently have an adequate explanation for this result. The MC-ICPMS value should represent the maximum possible ${ }^{129} \mathrm{I} /{ }^{127} \mathrm{I}$ ratio for this sample, since the mass 129 signal includes contributions from interfering masses. It is possible that the AMS measurement somehow over-predicted the true ${ }^{129} \mathrm{I} /{ }^{127} \mathrm{I}$ ratio for the Almendro sample, perhaps due to an error in the measured iodide concentration of the water (which is determined by ion chromatography prior to performing the AMS analysis).

Table 2. ${ }^{129} \mathrm{I} /{ }^{127} \mathrm{I}$ analyses determined by AMS

\begin{tabular}{llcccc}
\hline Well Name & Test Name & Sample Date & $\begin{array}{c}\text { Total Dissolved } \\
\text { Iodine }(\mu \mathrm{g} / \mathrm{L})\end{array}$ & $\begin{array}{c}{ }^{129} \mathrm{I} /{ }^{127} \mathrm{I} \\
(\text { ratio })\end{array}$ & $\begin{array}{c}{ }^{129} \mathrm{I} \\
(\mathrm{pCi} / \mathrm{L})\end{array}$ \\
\hline U-20n PS\#1ddh & Cheshire & 12 Oct 99 & 13 & $4.91 \mathrm{E}-05$ & $1.14 \mathrm{E}-01$ \\
U-19q PS\#1d & Camembert & 21 Oct 98 & 10 & $2.27 \mathrm{E}-06$ & $4.07 \mathrm{E}-03$ \\
U-19v PS\#1ds & Almendro & 18 Aug 99 & 1 & $7.81 \mathrm{E}-03$ & $1.40 \mathrm{E}+00$ \\
& & & & & \\
U-19v PS\#1ds & Almendro & 31 May 01 & 1.2 & $1.09 \mathrm{E}-02$ & $2.34 \mathrm{E}+00$ \\
ER-20-5 \#3 & Tybo/Benham & 15 Nov 01 & 0.5 & $1.34 \mathrm{E}-05$ & $1.20 \mathrm{E}-03$ \\
UE-2ce & Nash & 22 Aug 01 & 7.4 & $2.40 \mathrm{E}-05$ & $3.18 \mathrm{E}-02$ \\
UE-7nS & Bourbon & 21 Aug 01 & 19.4 & $1.75 \mathrm{E}-07$ & $6.05 \mathrm{E}-04$ \\
U-4u PS\#2a & Dalhart & 16 Aug 99 & 3 & $5.32 \mathrm{E}-05$ & $2.85 \mathrm{E}-02$ \\
U-3cn PS\#2 & Bilby & 18 Dec 01 & 1.2 & $7.38 \mathrm{E}-04$ & $1.58 \mathrm{E}-01$ \\
\hline
\end{tabular}




\section{Conclusions and Recommendations}

If we assume that AMS ${ }^{129} \mathrm{I} /{ }^{127} \mathrm{I}$ measurements provide a reasonable means of verifying the MC-ICPMS results (probably a good assumption), the data presented here show the MC-ICPMS method is not yet developed to the point of producing reliable results for natural samples. When ${ }^{129} \mathrm{I} /{ }^{127} \mathrm{I}$ reference standards are dissolved in a pure water matrix and measured on the MC-ICPMS, the blank-subtracted values are reproduced with less than $10 \%$ error (Table 1), down to a detection limit of around 1E-6. This detection limit is sufficient to measure all but one of the near-field samples listed in Table 2, once the mass interference issue is resolved. In order to settle this problem, it is necessary to reduce the molybdenum concentration in the purified samples to a level where we can add oxygen gas into the collision cell without creating an interference at mass 129 from ${ }^{97} \mathrm{Mo}^{16} \mathrm{O}_{2}$. The oxygen gas will in turn significantly reduce the ${ }^{129} \mathrm{Xe}$ mass interference. Corrections for the ${ }^{127} \mathrm{IHH}$ interference can then be developed by measuring the mass 129 background while running ${ }^{129}$ I-free iodide reference standards that are prepared using the same procedure as used for natural samples.

The molybdenum problem was unforeseen, and has been difficult to reconcile. Precipitating the molybdenum as an insoluble salt (such as $\mathrm{PbMoO}_{4}$ ) reduces the concentration of dissolved Mo to sub-ppb levels - but even with pre-concentrating the iodine, the tiny amount of ${ }^{97} \mathrm{Mo}$ that is present in solution is sufficient to create a significant mass interference. Completely eliminating the Mo interference will probably require a chemical process that involves adding a Mo isotope spike to the sample, and then precipitating the molybdate ion $\left(\mathrm{MoO}_{4}{ }^{2-}\right)$. For example, the stable isotope ${ }^{92} \mathrm{Mo}$ will not create any oxide mass interferences at mass 127 or 129 . After adding a dilute ${ }^{92} \mathrm{MoO}_{4}{ }^{2-}$ solution to the sample, the overwhelming majority the dissolved Mo will have a mass of 92. The Mo can then be chemically precipitated as before. Although the total concentration of Mo remaining in the sample will still be at the sub-ppb level (as before), nearly all of the ${ }^{97} \mathrm{Mo}$ will have been removed. If necessary, this step can be repeated to effectively eliminate all of the ${ }^{97} \mathrm{Mo}$.

High purity stable isotopes of molybdenum are commercially available, but are rather expensive (around \$1,000 per gram). However, the quantity of Mo spike that needs to be added to the sample is so small that it should be possible to process hundreds of samples with one gram of ${ }^{92} \mathrm{Mo}$ starting material. Once the Mo interference is eliminated, the remainder of the mass interference issues should be resolvable, as outlined above. We will continue testing and refining the procedure for ${ }^{129} \mathrm{I} /{ }^{127} \mathrm{I}$ analysis on the MC-ICPMS during FY04 using LLNL internal funding (LDRD). 


\section{References Cited}

Fabryka-Martin, J. (2000) Iodine-129 as a groundwater tracer. In: Cook, P.G. and Herczeg, A.L. (eds.) Environmental Tracers in Subsurface Hydrology, Kluwer, Boston, pp. 504-510.

Fabryka-Martin, J., Davis, S.N., and Elmore, D. (1987) Applications of ${ }^{129} \mathrm{I}$ and ${ }^{36} \mathrm{Cl}$ in hydrology. Nucl. Instrum. Meth. Phys. Res., B29, 361-371.

Fehn, U., Holdren, G.R., Elmore, D., Brunelle, T., Teng, R., and Kubik, P.W. (1986) Determination of natural and anthropogenic I-129 in marine sediments. Geophys. Res. Lett., 13, 137-139.

Moran, J.E., Fehn, U., and Teng, R.T.D. (1998) Variations in ${ }^{129} \mathrm{I} / \mathrm{I}$ ratios in recent marine sediments: Evidence for a fossil organic component. Chem. Geol., 152, 193-203. 


\section{Appendix A}

\section{Purification of lodine from Groundwater Samples for ${ }^{129} \mathrm{I} /{ }^{127}$ I Analysis by MC-ICPMS}




\section{Scope of Analytical Technique}

1.1 The purpose of this document is to describe the procedure used by the Chemical Biology and Nuclear Science Division (CBND) of Lawrence Livermore National Laboratory (LLNL) to extract the iodide anion ( $\left(^{-}\right)$from environmental water samples. Iodide samples are analyzed for their ${ }^{129} \mathrm{I} /{ }^{127} \mathrm{I}$ isotopic ratio by Multi-Collector Inductively Coupled Plasma Mass Spectrometry (MC-ICPMS). Analyses support hydrologic characterization of Nevada Test Site (NTS) groundwater by the National Nuclear Security Administration, Nevada Site Office, Environmental Restoration Division.

1.2 ${ }^{129} \mathrm{I}$ is a fission product produced during underground nuclear tests and has a half-life of $1.57 \times 10^{7}$ years. It is inferred to have a high mobility as iodide ions in groundwater.

\section{Equipment and Reagents List}

300 microliter resin bed size homemade columns fabricated from transfer pipets BioRad ${ }^{\circledR}$ Poly-Prep columns or similar to accommodate a $2 \mathrm{~mL}$ resin bed BioRad® AG50W-X8 100-200 mesh cation exchange resin, $\mathrm{NH}_{4}{ }^{+}$form BioRad ${ }^{\circ}$ AG50W-X8 200-400 mesh cation exchange resin, $\mathrm{H}^{+}$form Borosilicate glass beakers - various sizes $250 \mathrm{~mL}$ and $500 \mathrm{~mL}$ Teflon FEP separatory funnels and ring stand Hot plates Heat lamps $15 \mathrm{~mL}$ conical bottom polypropylene centrifuge tubes $10 \mathrm{~mL}$ glass centrifuge cones with screw-top closure pasteur pipets and plastic transfer pipets Autopipettes with disposable tips Water filtration pump and 0.45 micron high-flow filter cartridges $\mathrm{pH}$ test strips - various ranges MQ $\mathrm{H}_{2} \mathrm{O}$ $0.1 \mathrm{M}$ Hydroxylamine Hydrochloride $\left(\mathrm{NH}_{2} \mathrm{OH} \cdot \mathrm{HCl}\right)$ solution $1 \mathrm{M}$ Silver nitrate solution $\left(\mathrm{AgNO}_{3}\right)$ $1 \mathrm{M}$ Potassium cyanide solution $(\mathrm{KCN})$ Molybdenum standard solution (1000 micrograms $/ \mathrm{mL}$ ) in water BioRad® AG50W-X8 (100-200 mesh) cation resin Concentrated ammonia solution (ca. $22 \%$ ammonia)* $50 \%$ ammonia solution (approximately $6 \mathrm{M} \mathrm{NH}_{4} \mathrm{OH}$ ) from concentrated Hydrochloric acid (conc. $\mathrm{HCl}$ ) and $0.1 \mathrm{M} \mathrm{HCl}$ solution* Nitric acid (conc. $\mathrm{HNO}_{3}$ ) and $2 \% \mathrm{HNO}_{3}$ solution $(\mathrm{v} / \mathrm{v})$ *

*All acids are SeaStar ${ }^{\circledR}$ - sub-boiling double distilled in quartz. Ammonia solution is SeaStar ${ }^{\circledR}$.

\section{References}


3.1 Lagarde-Simonoff, M., M. Baklouti, S. Regnier and G.N. Simonoff, Chemical Separation of ${ }^{36} \mathrm{Cl}$ formed by nuclear reactions in Fe, Ti and Ca Targets, $J$. Inorg. Nucl. Chem., 1977, v. 39, pp. 1710-1711.

\subsection{LLNL Health and Safety Manual.}

\section{Definitions}

MC-ICPMS - Multi-Collector Inductively Coupled Plasma Mass Spectrometry

$\mathrm{I}^{-}$- Iodide (the anionic form of the element iodine).

$\mathrm{HAHCl}$ - Hydroxylamine Hydrochloride $\left(\mathrm{NH}_{2} \mathrm{OH} \cdot \mathrm{HCl}\right)$

$\mathrm{MQ} \mathrm{H}_{2} \mathrm{O}-\mathrm{Milli}-\mathrm{Q}{ }^{\circledR} 18 \mathrm{MOhm}-\mathrm{cm}$ resistivity reagent grade water

\section{Personnel Requirements and Training}

5.1 All personnel are responsible for performing their work safely. Particular consideration should be given to the following:

5.2 Handling of samples involves potential exposure to hazardous chemicals. All personnel performing such work shall follow all applicable facility and operational procedures.

5.3 Standard good laboratory practice requires wearing safety glasses, protective clothing such as a lab coat, and proper gloves when working with chemicals or radioactive materials.

\section{Analytical Procedures}

6.1 Chloride $\left(\mathrm{Cl}^{-}\right)$and, where possible, iodide $\left(\mathrm{I}^{-}\right)$concentrations in each water sample are determined by ion chromatography. Un-acidified water samples are used for iodide analyses. Preservation of water in the field with hydroxylamine hydrochloride $(\mathrm{HAHCl})$ to keep iodine in anionic form is preferred. Five $\mathrm{mL}$ of $0.1 \mathrm{M}$ HAHCL should be added per liter of water.

6.2 If the iodide concentrations are available, calculate the volume of water required to obtain at least $5 \mathrm{ug}$ (micrograms) of I. (It may be necessary to estimate $\mathrm{I}^{-}$ from the $\mathrm{Cl}^{-}$). Filter the sample and then weigh the calculated amount of water into an appropriately sized borosilicate glass beaker. Assume the density of the water is 1.00 grams $/ \mathrm{mL}$. If more than 2 liters are required, multiple beakers of the same sample may be started and the samples combined later. If the water sample was not preserved for iodine analyses upon collection, add $0.1 \mathrm{M}$ $\mathrm{HAHCl}$ at $5 \mathrm{~mL}$ per liter of water. Evaporate the sample by $80 \%$ on a hot plate without boiling. That is, reduce the volume of a one-liter sample to approximately $200 \mathrm{~mL}$ or a 2-liter sample to approximately $400 \mathrm{~mL}$. Transfer the sample with MQ water rinses into a Teflon separatory funnel. 
6.3 Test the sample $\mathrm{pH}$ and adjust to between 1 and 1.6 by adding $\mathrm{HNO}_{3}$. Swirl the sample in the separatory funnel and slowly add enough $1 \mathrm{M} \mathrm{AgNO}_{3}$ solution to provide a $2 \mathrm{X}$ stoichiometric excess of $\mathrm{Ag}^{+}$for the amount of $\mathrm{Cl}^{-}$in the sample. Be sure to include the $\mathrm{Cl}^{-}$from the $\mathrm{HAHCl}$ in the calculations. Cap the sample and mix thoroughly. Place in the ring-stand, loosen the cap, and heat the sample with heat lamps to assist coagulation of the $\mathrm{AgCl}+\mathrm{AgI}$ precipitate (ppt). Agitate the sample occasionally during heating and bring to a boil with the heat lamps (two lamps per separatory funnel). Allow the sample to cool and the ppt to settle.

6.4 Assist the settling of the ppt by rotating the separatory funnel abruptly and tapping the walls. After it has settled, drain the ppt through the stopcock into a $15 \mathrm{~mL}$ polypropylene centrifuge tube. Essentially quantitative transfer can be accomplished in less than $15 \mathrm{~mL}$ volume in two increments as follows: close the stopcock after the bulk of the ppt has drained through and swirl the sample in the funnel gently to dislodge residual ppt; allow it to settle and drain this second fraction into the tube.

6.5 Centrifuge and decant the supernatant to waste. Hot well samples may contain tritium and the waste needs to be segregated and disposed of accordingly. Resuspend the ppt in $2 \% \mathrm{HNO}_{3}$, centrifuge and decant the supernate to waste. Re-suspend again in $2 \% \mathrm{HNO}_{3}$ and transfer the sample to a $10 \mathrm{~mL}$ glass centrifuge cone, centrifuge and decant the supernate to waste.

6.6 Continue to rinse the ppt, centrifuge and decant the supernate to waste. First, rinse with MQ water, then with $0.1 \mathrm{M} \mathrm{HCl}$, and then again with MQ water.

6.7 Add a few drops of conc. ammonia and about two $\mathrm{mL}$ of $50 \%$ ammonia solution to the sample. Agitate the ppt with a pasteur pipet to dissolve the $\mathrm{AgCl}$. Centrifuge. The AgI will remain as an insoluble ppt, which generally appears as a small dark pellet. Remove and discard the supernate using the pasteur pipet. Add another $2 \mathrm{~mL}$ of $50 \%$ ammonia to the ppt, agitate, centrifuge and discard the supernate.

6.8 Dissolve the AgI ppt with $0.02 \mathrm{~mL}$ of $1 \mathrm{M} \mathrm{KCN}$ solution added to a few drops of $50 \%$ ammonia. Use the pasteur pipet to stir, and police the centrifuge cone. Rinse down the walls with $0.5 \mathrm{~mL}$ of $50 \%$ ammonia, stir, centrifuge briefly, and check that the sample is completely dissolved.

6.9 Prepare a 1.5 mL resin bed of BioRad ${ }^{\circledR}$ AG50W-X8 (100-200 mesh) cation exchange resin in a Poly-Prep column. Condition the resin bed with about 10 $\mathrm{mL}$ of $50 \%$ ammonia solution. Suspend the resin in the ammonia solution and allow it to settle to condition it and to eliminate gas bubbles in the resin bed. Place a clean $10 \mathrm{~mL}$ glass centrifuge cone below the column and load the sample solution on the resin. Allow the sample to pass and then rinse it through with $0.5 \mathrm{~mL}$ and then one $\mathrm{mL}$ of $50 \%$ ammonia. This column adsorbs the $\mathrm{K}+$ 
and any $\mathrm{Ag}\left(\mathrm{NH}_{3}\right)_{2}+$, while the anions (and $\mathrm{I}^{-}, \mathrm{Cl}^{-}$and $\mathrm{CN}^{-}$)pass with the ammonia.

6.10 Evaporate the sample, which will be in approximately $1.5 \mathrm{~mL}$ of $50 \%$ ammonia solution, in a hot water bath on a hotplate and with a heat-lamp to assist. Reduce the volume to about $0.5 \mathrm{~mL}$ and remove from the hot water bath.

6.11 Prepare a $0.3 \mathrm{~mL}$ resin bed from BioRad® AG50W-X8, 200-400 mesh, cation exchange resin in a homemade mini-column. Rinse the resin with MQ water and condition with $1 \mathrm{~mL}$ of $6 \mathrm{M} \mathrm{HCl}$, followed by $1 \mathrm{~mL}$ of MQ water.

6.12 Place a $10 \mathrm{~mL}$ glass sample tube under the column to catch the sample and load the cooled sample solution from step 6.10 onto the column. Again, the anions pass, and any residual cations which includes NH4+ are adsorbed. Rinse the sample tube with $0.5 \mathrm{~mL}$ of MQ water and load this on the resin bed after the load has passed through. Repeat this rinse. The $\mathrm{I}^{-}$sample will be in approximately $1.5 \mathrm{~mL}$ of a weakly acidic $\mathrm{HCl}$ solution.

6.13 If it is necessary to concentrate the sample prior to analysis, the volume can be reduced to $1 \mathrm{~mL}$ or less a hot water bath as in step 6.10. Make sure the sample tube is capped securely and labeled. The sample is ready for ${ }^{129} \mathrm{I} /{ }^{127} \mathrm{I}$ analysis by MC-ICPMS.

\section{Procedural and Equipment Calibration}

7.1 Blanks - A procedural blank is run with every batch of samples.

7.2 Calibration - Multiple NIST standards are run with every sample batch to determine and correct for instrumental mass bias and relative detector gains. Pure ${ }^{127}$ I standards are used to determine and correct for interference from $\mathrm{IHH}^{+}$ at mass 129 . Pure ${ }^{127}$ I standards with molybdenum added are used to determine correction factors for possible $\mathrm{Mo}-\mathrm{O}-\mathrm{O}^{+}$interferences resulting from residual molybdenum in the sample.

\section{Safety Precautions}

8.1 Good laboratory practice mandates wearing safety glasses, protective clothing such as a lab coat, and proper gloves when handling potentially hazardous and/or radioactive samples.

8.2 Samples are screened for radioactivity in the field laboratory at NTS prior to transportation to LLNL.

8.3 Samples with a screening value greater than $1000 \mathrm{dpm} / \mathrm{ml}(\mathrm{g})$ shall be considered 'hot'. 
8.4 'Hot' samples shall be conspicuously labeled.

8.5 Potassium cyanide $(\mathrm{KCN})$ is very poisonous. Only minute amounts of dilute solution are used in this procedure and ordinary personal protective equipment and good laboratory practice are sufficient protection. Even so, the analyst is advised to read the available literature on cyanide handling and safety practice. Further, the evolution of extremely toxic hydrogen cyanide gas is possible when samples containing cyanide are acidified. All procedures (evaporations and column purifications) involving the sample after the $\mathrm{KCN}$ solution is added should be performed in a fume hood. 